\title{
Laser ablation inductively coupled plasma mass spectrometry (LA-ICP-MS) for spatially resolved trace analysis of early-medieval archaeological iron finds
}

\author{
Received: 15 July 1999 / Revised: 11 October 1999 / Accepted: 15 October 1999
}

\begin{abstract}
The suitability of laser ablation ICP-MS for minor and trace analysis of archaeological iron finds, produced by a direct reduction process in a 'bloomery' furnace, is reported. The analysis of elemental impurities in the iron can provide useful archaeometallurgical information on the production process and the provenance of the iron. Since, even after refinement, the iron resulting from this process may contain many inclusions (slag, charcoal, holes, etc.), a method should be used with sufficient spatial resolution to preclude the inclusions from the analysis. The ablation parameters are selected such that ablation craters of approx. $100 \mu \mathrm{m}$ in diameter are obtained. The method is validated with low alloy steel and cast iron standard reference materials and by a comparative analysis with electron probe microanalysis (EPMA). The precision is limited mainly by the homogeneity of the iron, rather than by instrumental reproducibility. The advantages and drawbacks of the method are briefly compared with EPMA. Preliminary results from the analysis of archaeological iron samples from excavations at DevelierCourtételle (Canton Jura, CH), Neftenbach (Canton Zurich, $\mathrm{CH}$ ), Wartau (Canton St Gallen, $\mathrm{CH}$ ) and Mont Chemin (Canton Valais, $\mathrm{CH}$ ) are given.
\end{abstract}

\section{Introduction}

Archaeological excavations at the site of DevelierCourtételle, situated in the Swiss Jura, revealed early medieval (ca. $600 \mathrm{AD}$ ) remains of extensive iron forging activity in the form of smithies, iron objects, intermediate

W. Devos (凶) $\cdot$ M. Senn-Luder · C. Moor

Swiss Federal Laboratories

for Materials Testing and Research (EMPA),

Überlandstrasse 129, CH-8600 Dübendorf, Switzerland

C. Salter

Materials Science-Based Archaeology Group, Department of Materials, University of Oxford, Parks Rd, OX1 3PH, UK iron products from different refining stages and numerous waste products [1]. In this era and region, iron was produced in a so-called 'tap-slag' or 'bloomery' furnace, by a direct reduction process in which no liquefaction of the iron took place. The resulting product, called 'iron bloom', was a very heterogeneous, spongy metal, mixed with slag and charcoal, which then had to be further refined by a blacksmith to eliminate most of the impurities [2]. The quality of the iron can be studied by metallographic examination of polished cross-sections under a microscope. From chemical analysis, archaeologists and archaeometallurgists expect to obtain information on the chemical behaviour of typical elemental impurities in the iron through different stages of refinement. Furthermore, they hope to find answers to several questions, which arose in the context of the excavation, such as: Were the finished iron tools, excavated on the site, really locally produced? Is it possible to establish a link between the iron produced at this site and local iron ores? Can iron from Develier-Courtételle be distinguished from iron from other sites by its chemical composition?

Since the samples under investigation (iron bloom, intermediate products, refined iron and finished objects) may contain many inclusions, e.g., corrosion, slag, holes, or even charcoal (Fig. 1), which should be excluded from the analysis, X-ray fluorescence (XRF), spark source optical emission spectrometry (SS-OES) or a wet analytical method cannot be used. Instead, an analytical technique for solid samples should be used with sufficient spatial resolution to allow trace element analysis of the iron while avoiding the inclusions. Moreover, the method of choice should preferably have detection limits in the lower $\mu \mathrm{g} / \mathrm{g}$-range or better. Proton induced X-ray emission spectrometry (PIXE) can provide a spatial resolution ranging from $>1 \mathrm{~mm}$ to a few $\mu \mathrm{m}$ [3]. Several studies have been published illustrating its application as a proton milli- and microprobe in archaeometallurgical research [4-7]. However, it is quite an expensive method, since a proton accelerator is needed. Moreover, in thick target PIXE analysis of matrices containing medium or heavy elements $(Z>20)$, the minimum detection limits are gen- 


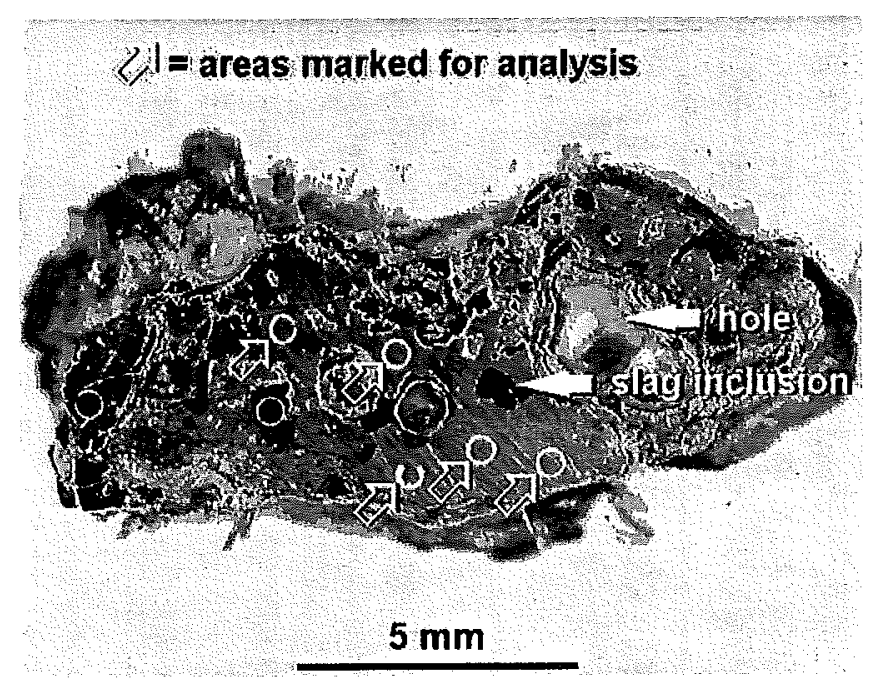

Fig. 1 Optical microscopy view of a cross-section of an iron bloom fragment embedded in a synthetic resin

erally higher by at least two orders of magnitude compared to those achievable for low $Z$ matrices $(Z \leq 20)$, and the determination of traces is therefore limited [8]. Hence, micro-PIXE has been applied mostly for the determination of major and minor elements in archaeometallurgy. The latter also applies to energy-dispersive X-ray fluorescence analysis coupled to a scanning electron microscope (SEMEDXRF). Although SEM-EDXRF offers a lateral resolution in the $\mu \mathrm{m}$-range, its detection limits of $0.1 \%$, at best, are insufficient for the current application. The main technique currently used in archaeometallurgy for the microanalysis of minor and trace elements in metallographic sections, is probably electron probe microanalysis (EPMA), i.e., the combination of wavelength-dispersive $X$-ray fluorescence analysis (WDXRF) with SEM. Owing to much better signal-to-noise ratios, the detection limits of EPMA are about two orders of magnitude better than those of SEM-EDXRF. EPMA has proved its merits in archaeometallurgy as a method for point analysis (spatial resolution 1-50 $\mu \mathrm{m}$ ) and element mapping of heterogeneous samples, and has been used frequently for the analysis of heterogeneous archaeological iron samples [9-11].

In this study, the aforementioned requirements were fulfilled by using laser ablation in combination with inductively coupled plasma mass spectrometry (LA-ICP-MS). Thanks to its wide linear dynamic range, its low detection limits, its low sample consumption and its spatial resolution capabilities within a range from approximately a few $\mu \mathrm{m}$ up to $1 \mathrm{~mm}$ [12-16], laser ablation ICP-MS has undergone rapid development in the past one and a half decades and has seen application in diverse fields as a solid sampling method for both bulk and space resolved analysis. However, its widespread use as a quantitative analytical method has been partially hampered by the more or less cumbersome calibration strategies needed when commercial matrix-matched standards are not available [15-25].
Ishibashi reported the use of a $1064 \mathrm{~nm} \mathrm{cw}-\mathrm{Q}$-switched Nd:YAG laser in combination with ICP-MS to perform line scans with a $1 \mathrm{~mm}^{2}$ laser beam diameter for quantitative bulk analysis of modern industrial steels [26]. In archaeometallurgy, LA-ICP-MS has been applied by Shell et al. [27] for fingerprint analysis of archaeological gold samples with minimal sample damage, without quantifying the analyte signals in terms of concentrations though. The aim of this work is to validate the application of LA-ICP-MS analysis for space-resolved, quantitative analysis of archaeological iron samples, using commercially available reference materials for calibration, and the method is briefly compared with EPMA. It is demonstrated that LA-ICP-MS could be a useful alternative to EPMA for this type of application.

\section{Experimental}

Sample preparation. The archaeological samples were embedded in a synthetic Plexiglas resin (RESINAR $F$, Wirtz Buehler, Diusseldorf, Germany) or an epoxy resin (ARALDITE BY 158, Ciba Corp., Basel, Switzerland) and polished cross-sections were prepared. After metallographic examination, inclusion-free areas were marked for analysis with a circle under the optical microscope (Fig. 1), using a diamond point. The standard discs (see calibration) were also polished before analysis, to remove contamination and earlier craters. Finally, the sample surface was cleaned with deionised water and p.a. ethanol.

Instrumentation and experimental parameters. A Perkin-Elmer Laser Sampler Model 320, modified with a home-built autofocus system [28], was used in combination with a Perkin-Elmer SCIEX Elan 6000 ICP-MS. The Nd:YAG laser (Spectra-Physics, Darmstadt, Germany) was operated at $532 \mathrm{~nm}$. The area of ablation could be observed with a video camera. Measurements were performed in the extended range detection mode of the Elan 6000 , which offers measuring pulse-counting and analogue signals simultaneously [29].

The carrier gas flow rate was optimised for maximum signal intensity with an iron standard material. The excitation lamp energy, which directly influences the laser beam energy, and the number of pulses per analysis point were chosen such that ablation craters of ca. 80-100 $\mu \mathrm{m}$ across and about 35-45 $\mu \mathrm{m}$ deep were obtained (Fig. 2). The width of the crater is mainly determined by the first parameter, whereas the depth is influenced by both parameters. Microscopic examination of the samples under study showed that a resolution of $100 \mu \mathrm{m}$ should be sufficient to avoid holes, corroded areas and inclusions like slags or charcoal. Although crater of a smaller size could be obtained, smaller craters would decrease the relative sensitivity and are considered to be less representative of the iron composition. From the crater width and depth, the ablated mass per crater could be very roughly estimated to be around $0.5-1 \mu \mathrm{g}$.

It can be seen from Fig. 2 that not only the form of the craters, shot within one sample and one analysis run, but even the associated melting effects are amazingly reproducible. The repeatability for the integrated iron signal was generally below $5 \%$ within one sample. However, between different samples or between samples and standards, small differences in the crater size sometimes occurred, possibly due to slight differences in hardness or thermal conductivity of the samples, e.g., depending on the carbon content. Since the iron content is either accurately known (for the standards) or close to $100 \%$ (for the samples), the iron signal could be used for internal standardisation and the analyte signals were normalised to the $\mathrm{Fe}$ signal to correct for differences in ablation efficiency. 


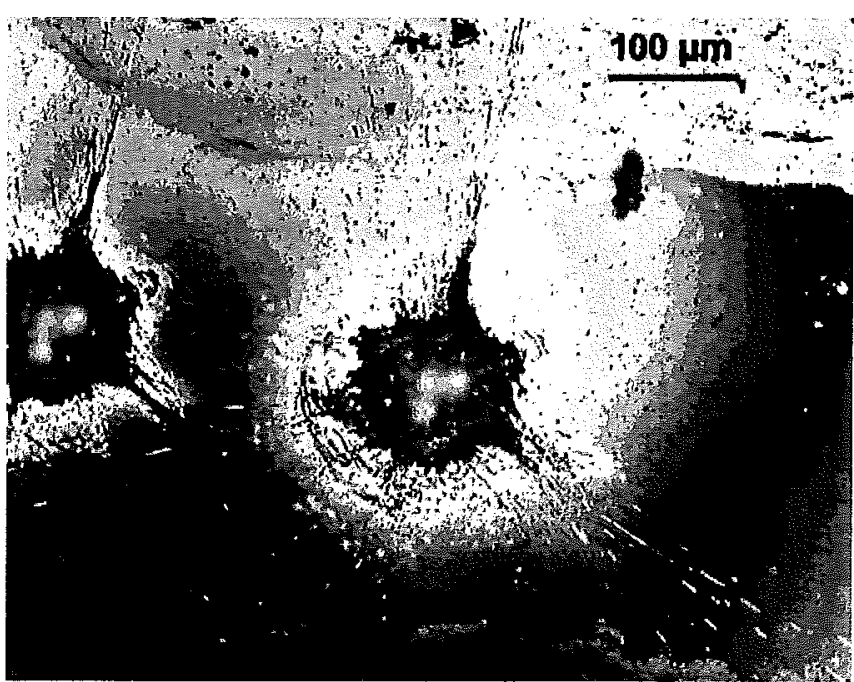

Fig. 2 Optical microscopy view of 2 laser ablation craters in iron, sandwiched between 2 corrosion layers (upper and lower figure margins)

The selection of the elements to be measured was based on their potential archaeometallurgical relevance and on the availability of certified values in the standards. To obtain similar ablation conditions for external standards and samples, standard materials with chemical and physical properties very similar to the samples are to be preferred in laser ablation analysis. Although there are numerous commercially available steel standards on the market, mainly intended for XRF and SS-OES analysis, the calibration of a large number of elements in their appropriate concentration range would require many external standards to be measured. The elements chosen here were $\mathrm{Al}, \mathrm{P}, \mathrm{V}, \mathrm{Cr}, \mathrm{Mn}, \mathrm{Co}, \mathrm{Ni}, \mathrm{Cu}$ and $\mathrm{As}$. They were calibrated with two external solid standards: one lowalloy steel NIST1262;0.16\% C) from NIST (Gaithersburg MD, USA) and a cast iron (ARL1721; 3.52\% C) from ARL (Ecublens, Switzerland) (Table 1). The calibration was carried out once or twice per measuring day, depending on the number of samples. The transient signals, resulting from firing the laser for $2 \mathrm{~s}(10 \mathrm{~Hz}$ -20 pulses), started rising rapidly after 2-3 s and decreased back to background level within $30 \mathrm{~s}$ or less (depending on the concentration) for the minor and trace elements and within about $60 \mathrm{~s}$ for

Table 1 Elemental concentrations (\%) in the 2 standard materials used for calibration

\begin{tabular}{lll}
\hline Analyte & $\begin{array}{l}\text { NIST1262 }^{\mathrm{a}} \\
\text { (AISI 94B17 steel) }\end{array}$ & $\begin{array}{l}\text { ARL1721 } \\
\text { (cast iron) }\end{array}$ \\
\hline $\mathrm{Al}$ & $0.09_{5}$ & n.i. \\
$\mathrm{P}$ & 0.042 & 0.705 \\
$\mathrm{~V}$ & $0.04_{1}$ & 0.092 \\
$\mathrm{Cr}$ & 0.30 & 0.37 \\
$\mathrm{Mn}$ & 1.04 & 0.70 \\
$\mathrm{Co}$ & 0.30 & n.i. \\
$\mathrm{Ni}$ & 0.59 & 0.119 \\
$\mathrm{Cu}$ & 0.50 & 0.11 \\
$\mathrm{As}$ & $0.09_{2}$ & n.i. \\
\hline
\end{tabular}

n.i. $=$ not indicated

${ }^{\mathrm{a}}$ Uncertainties for NIST1262 are given as \pm 1 (resp. \pm 5 for a subscript figure) in the last significant figure reported

${ }^{\mathrm{b}}$ Uncertainties for ARL1721 were not given explicitly; therefore the same rule was applied as for NIST1262
Table 2 Operating conditions for the ICP mass spectrometer and the laser sampler

\begin{tabular}{ll}
\hline ICP mass spectrometer & Perkin Elmer SCIEX Elan 6000 \\
RF Power/W & 1050 \\
Gas flow rates/L min ${ }^{-1}:$ & \\
$\quad$ Plasma gas & 15 \\
$\quad$ Auxiliary gas & 0.8 \\
Carrier gas & 1.3 \\
Lens setting & Autolens Mode (variable) \\
Points per peak & 1 (at peak maximum) \\
Measuring mode & Peak-hopping \\
Isotopes measured & ${ }^{27} \mathrm{Al},{ }^{31 \mathrm{P},}{ }^{51} \mathrm{~V},{ }^{53} \mathrm{Cr},{ }^{55} \mathrm{Mn},{ }^{57} \mathrm{Fe}$ (internal \\
& standard), ${ }^{59} \mathrm{Co},{ }^{60} \mathrm{Ni},{ }^{63} \mathrm{Cu},{ }^{65} \mathrm{Cu},{ }^{75} \mathrm{As}$ \\
Dwell time/ms & 10 \\
Detector mode & Dual (pulse counting and analogue) \\
Laser sampler & Perkin-Elmer Laser Sampler Model 320 \\
Wavelength & 532 nm \\
Mode & Q-switch \\
Q-switch time/ $\mu \mathrm{s}$ & 240 \\
Excitation lamp energy/J & 45 \\
Pulse frequency/Hz & 10 \\
Number of pulses/ & 20 \\
$\quad$ analysis point & \\
Focus & On sample surface (autofocus)
\end{tabular}

the matrix element iron. Since the iron signal had already decreased down to $5 \%$ of its maximum intensity after $30 \mathrm{~s}$, the signals were integrated over a period of $30 \mathrm{~s}$ after the laser had started firing, thus covering the entire minor and trace analyte signals and most of the iron signal. A blank correction was carried out by subtracting the Argon gas blank signal, integrated over the same period of time and measured with the laser beam path blocked. The experimental parameters settings and the selected isotopes are summarised in Table 2.

For the archaeological samples, 5-10 spots per sample were measured. In order to eliminate the influence of outliers, median values instead of means were used for interpretation. Some samples consisted of several layers, in which case a median was calculated for each layer.

Comparative analysis with EPMA. One sample was analysed both by EPMA and LA-ICP-MS (in that order). The EPMA measurements were done on a Cameca SEMPROBE wavelength dispersive analytical scanning electron microprobe at the Research Laboratory for Archaeology and History of Art, University of Oxford. Prior to EPMA analysis, the sample was coated with carbon. In order to analyse approximately the same spot area as for the LA-ICPMS analysis, i.e. about $100 \mu \mathrm{m}$ in diameter, the electron beam diameter was widened. Defocusing the electron beam further than $50 \mu \mathrm{m}$ was not useful because of the limited observation angle of the collimator between the sample and the analyser crystal. Therefore, 5 neighbouring spots of $50 \mu \mathrm{m}$ across were measured, geometrically arranged such that the total analysed area approximately covered the diameter of the crater to be shot afterwards by laser ablation. Those 5 measurements were then averaged to one value per marked area. A current of $100 \mathrm{nA}$ and $100 \mathrm{~s}$ counting times were selected for all elements. The EPMA measurements were calibrated using external standards consisting of a mixture of mineral and pure element standards (supplied by C. Taylor, CA., USA and MAC, UK), and using the Cameca internal program to correct for mass absorption, fluorescent and atomic number factors. After EPMA analysis, the sample was briefly polished to remove the carbon coating. 

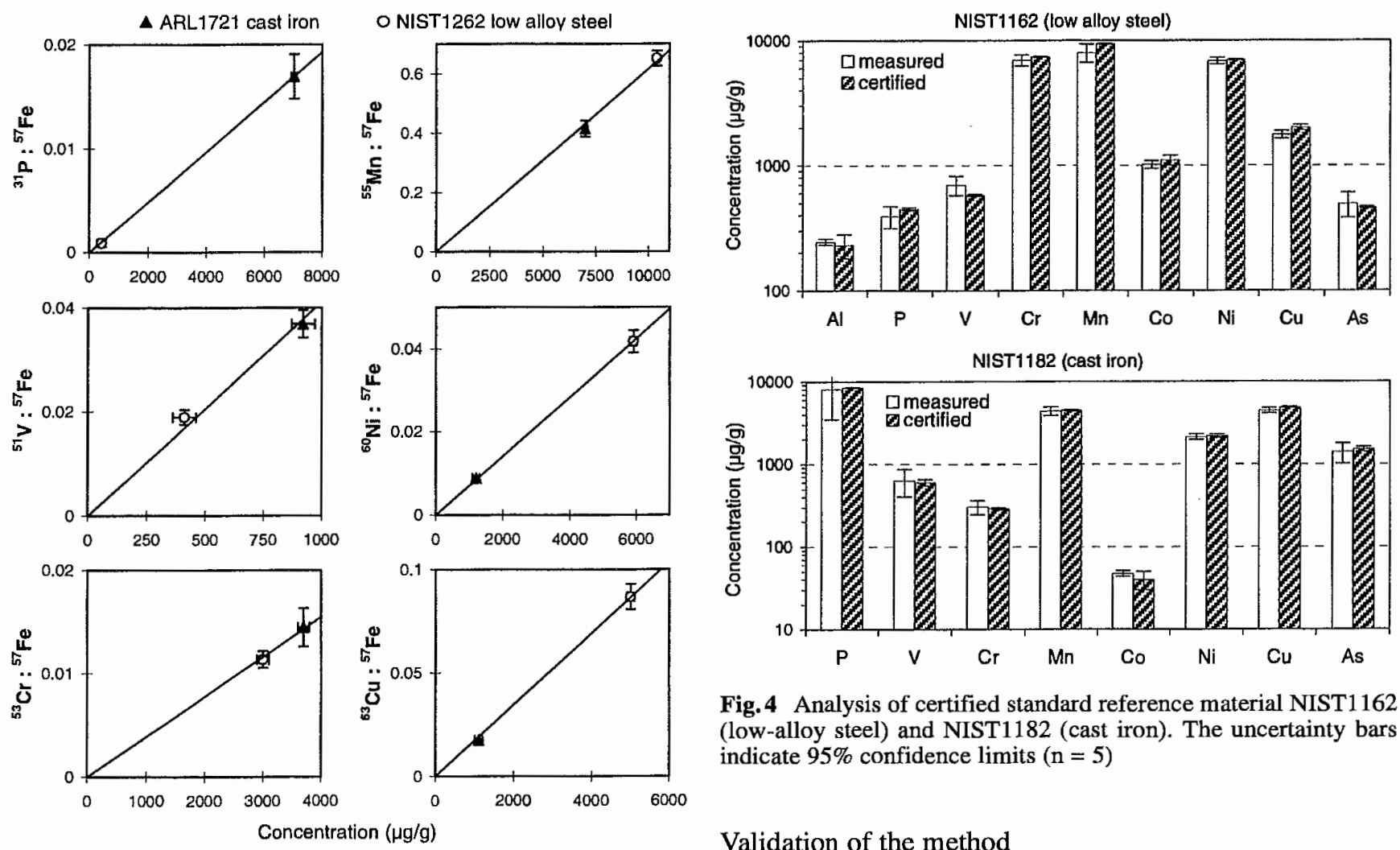

Fig. 4 Analysis of certified standard reference material NIST1162 (low-alloy steel) and NIST1182 (cast iron). The uncertainty bars indicate $95 \%$ confidence limits $(n=5)$

\section{Validation of the method}

Fig. 3 Three-point calibration graphs (including zero) for reference standards NIST1262 (low-alloy steel) and ARL1721 (cast iron). 5 points per standard were analysed. Concentration data for $\mathrm{Al}, \mathrm{Co}$ and $\mathrm{As}$ were not available for ARL1721

\section{Results and discussion}

\section{Calibration and detection limits}

The 3-point calibration graphs (including zero as a calibration point) for $\mathrm{P}, \mathrm{V}, \mathrm{Cr}, \mathrm{Mn}, \mathrm{Ni}$ and $\mathrm{Cu}$, based on the blank-subtracted analyte/ $/{ }^{57} \mathrm{Fe}$ signal ratios of 5 measuring spots each on the NIST low-alloy steel and the ARL cast iron, are shown in Fig. 3. The linearity of the calibration indicates that any errors by differences in ablation efficiency, for instance due to differences in carbon content, are accurately corrected for by internal standardisation. Since the Al-, Co- and As-concentrations were not known in ARL1721, a 2-point calibration (0 and NIST1262) was used to quantify these elements.

The detection limits ( $3 \sigma$ from 5 Ar-blank replicates) were generally below $1 \mu \mathrm{g} / \mathrm{g}$ for most elements. Chromium was determined by its minor isotope ${ }^{53} \mathrm{Cr}$ (abundance 9.5\%) to avoid the interference on the major isotope ${ }^{52} \mathrm{Cr}$ by ${ }^{40} \mathrm{Ar}^{12} \mathrm{C}^{+}$molecular ions, which can arise when samples with high carbon content are measured. This results in slightly higher detection limits for $\mathrm{Cr}$ (up to a few $\mu \mathrm{g} / \mathrm{g}$ ). Detection limits up to $30 \mu \mathrm{g} / \mathrm{g}$ were found for $\mathrm{P}$, due to background contribution by ${ }^{14} \mathrm{~N}^{16} \mathrm{O}^{1} \mathrm{H}^{+}$molecular ions on mass 31 .

The good linearity of the 3-point calibration graphs (including zero) already gave an indication of the reliability of the quantification. The method was further validated by analysing two other NIST certified standard reference materials, NIST1162 (low-alloy steel) and NIST1182 (cast iron), as if they were samples. The measured concentrations $(n=5)$ corresponded with the certified values within the experimental uncertainty (Fig. 4).

Additionally, ten inclusion-free areas were marked on one archaeological cast iron sample from DevelierCourtételle and measured consecutively by EPMA and LA-ICP-MS. Cast iron (C content $>2 \%$ ) has most probably only accidentally been produced at DevelierCourtételle and is therefore not entirely representative for the iron samples in this study. Nevertheless, a cast iron sample was selected for the comparative analysis because the $\mathrm{V}$ and $\mathrm{Mn}$ concentrations tend to be higher. In the majority of the plain iron or steel samples from DevelierCourtételle, the $\mathrm{V}$ - and possibly also the $\mathrm{Cr}$ - and $\mathrm{Mn}$-concentrations would have lain below the detection limits of EPMA. The results are given in Fig. 5. One value for $P$ and 2 values for $\mathrm{Mn}$ obtained with LA-ICP-MS are clearly outliers (Dixon's outlier test). The reason for these outliers is not entirely clear, but they might be caused by microsegregations of $\mathrm{P}$ and $\mathrm{Mn}$ into separate phases, below the surface of the cross-section (and thus invisible in the microscopic examination prior to analysis). Since the craters shot with the laser on the cross-sections are deeper than the information depth of the electron microprobe, one or more of such microsegregations may have been ablated by the laser while remaining undetected by the mi- 

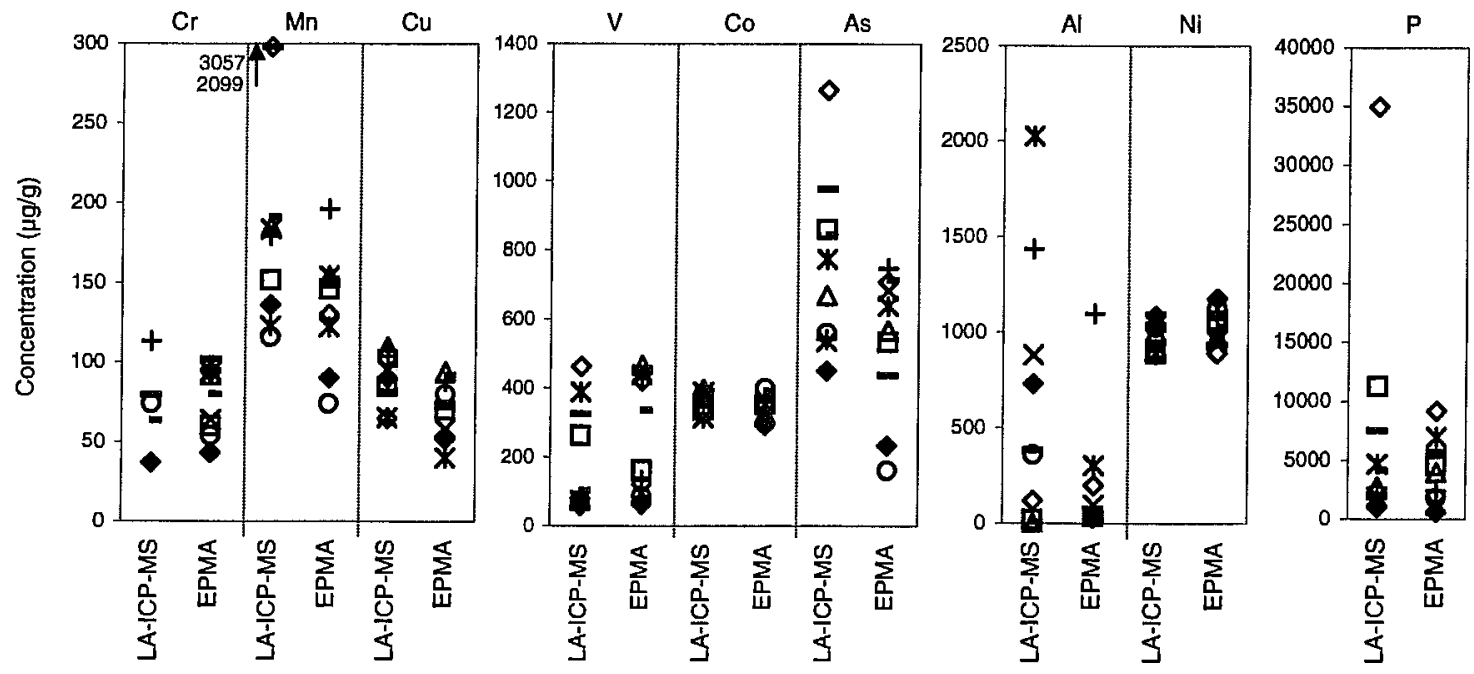

Fig. 5 Analysis of 10 points on an archaeological cast iron sample by LA-ICP-MS and EPMA

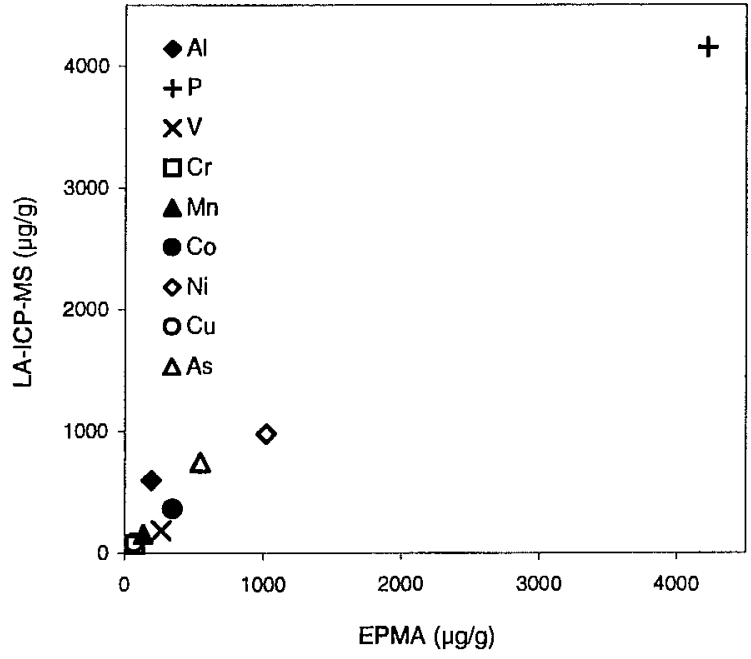

Fig. 6 Correlation plot for the mean values from 10 spots on an archaeological cast iron sample, measured by LA-ICP-MS and EPMA

croprobe. Such extreme P or Mn segregations can occur in a grey cast iron like the one sample analysed here and have also sporadically been noticed in some plain iron or steel waste products from Develier-Courtételle. For some elements, the corresponding values for an individual measuring spot do not agree very well, probably again because not exactly the same micro-volume of material could be measured, despite the attempts to adapt the spot area analysed by EPMA to the crater size of LA-ICP-MS. However, when considering the mean values, calculated from 10 spot analyses, the results for both methods correlate quite well (Fig.6). Although the mean values for $\mathrm{Al}$ from LA-ICP-MS and EPMA do not seem to be consistent in Fig. 6, a t-test $(P=0.05)$ indicated no statistically significant difference because the spreading of the $\mathrm{Al}$ values is very large.

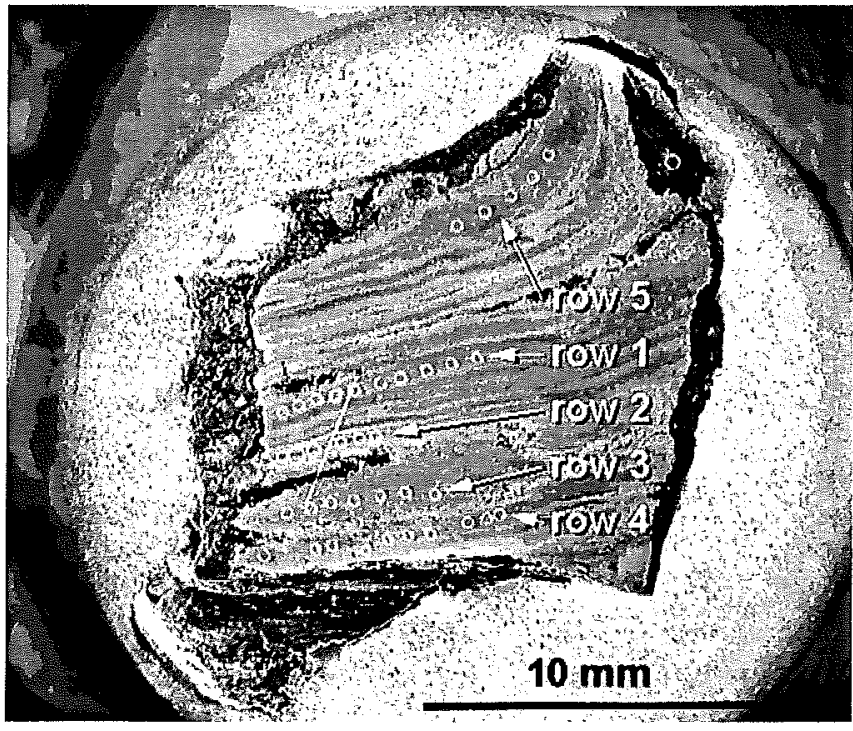

Fig. 7 Five rows of engraved circles on sample DEV44, parallel with the longitudinal forging direction, indicating the spots to be analysed by LA-ICP-MS. Row 1 : layer between between welding seems; row 2: alongside a lenticular iron enclosure; row 3: lenticular iron enclosure; row 4: close to the upper sample surface; row 5: close to the lower sample surface

\section{Repeatability}

The crater-to-crater repeatability of the normalised analyte signals for a homogeneous iron (e.g., the standards) is generally between $1-5 \%$ RSD $(n=5)$. The iron phase from the archaeological samples was usually less homogeneous. In an early medieval iron tool fragment (sample DEV44) from Develier, 39 points were measured in 5 rows, parallel with the longitudinal forging direction (Fig. 7). The results are shown in Fig. 8. Two main groups of elements can be distinguished. Elements such as $\mathrm{Al}, \mathrm{V}$, $\mathrm{Cr}$ and $\mathrm{Mn}$ are not homogeneously distributed in the iron (RSDs 30-150\%). These are 'lithophilic' elements, which typically tend to diffuse into the slags during the reduction process and are less soluble in the iron. The 'siderophilic' 


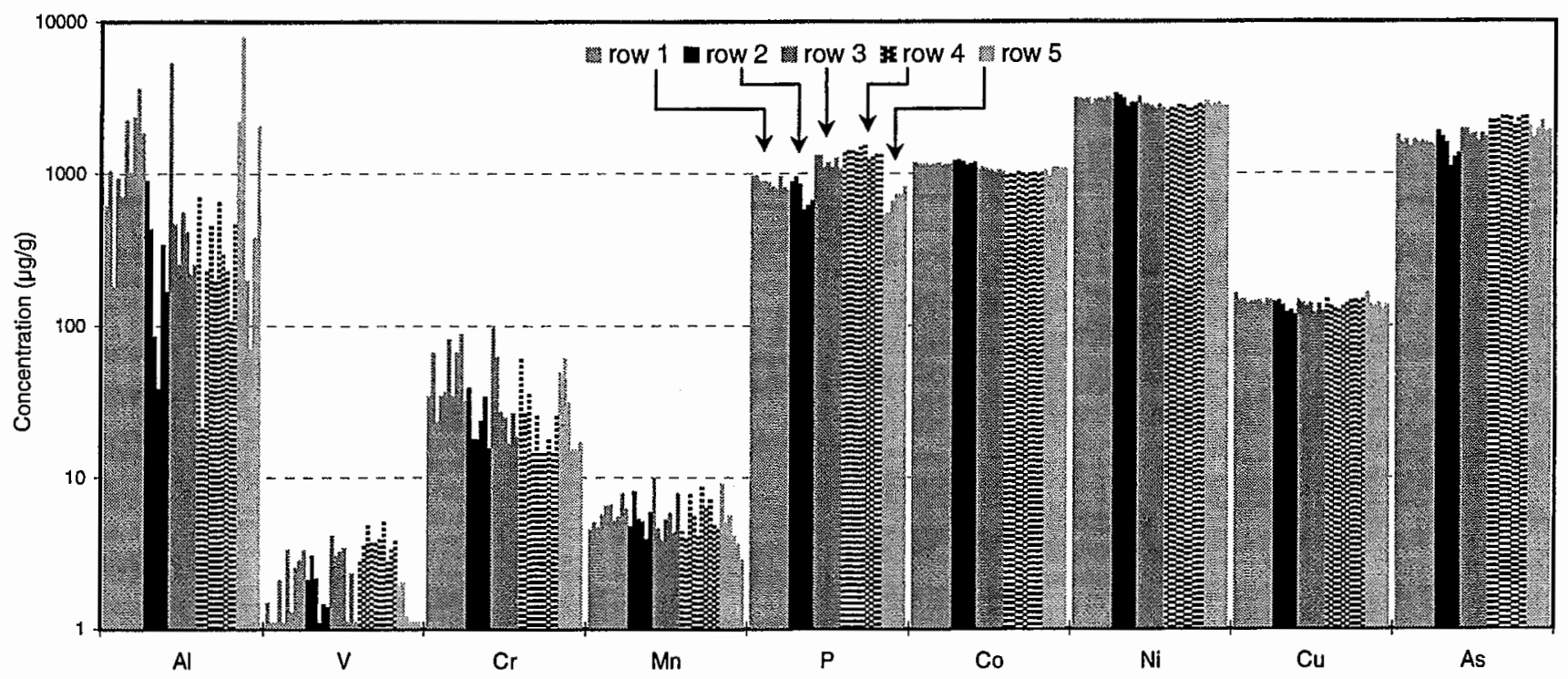

Fig. 8 Repeatability for the analysis of 39 points in an early medieval iron tool fragment (DEV44) from Develier, measured in 5 rows parallel with the longitudinal forging direction. RSDs are based on all 39 measurements

elements $\mathrm{Co}, \mathrm{Ni}, \mathrm{Cu}$ and $\mathrm{As}$ on the other hand, tend to associate with the iron during the reduction and are more homogeneously distributed. Phosphorus is fairly homogeneous within each row, but has a slightly different concentration from row to row. According to Crew and Salter, gradients in $\mathrm{P}$ concentrations can be caused by variations in smelting conditions and/or enrichment effects during forging. They observed segregation effects of $P$ in the form of detailed longitudinal bands in iron currency bars (albeit with higher $\mathrm{P}$ levels than in the sample here), which were experimentally reproduced from phosphorusrich bog ores according to a direct reduction process [11].

\section{LA-ICP-MS versus EPMA: pros and cons}

The detection limits of EPMA for this type of matrix are generally between 10 and $100 \mu \mathrm{g} / \mathrm{g}$ (with the best values for the range $12<\mathrm{Z}<22$ ). Except for $\mathrm{V}, \mathrm{Cr}$ and $\mathrm{Mn}$ (and $\mathrm{Ni}$ in the sample from Mont Chemin), these detection limits are sufficient for most of the other elements measured in the samples in this work. The major advantage of LA-ICP-MS over EPMA is its superior detection limit. For a wide range of elements in the periodic table, the detection limits of LA-ICP-MS are well below $1 \mu \mathrm{g} / \mathrm{g}$. Unfortunately, the spectral peaks of some elements of interest suffer from interferences by molecular species coming from the ambient air around the plasma or from matrix elements in the sample itself. Silicon, which is monoisotopic, is seriously interfered by ${ }^{14} \mathrm{~N}_{2}{ }^{+}$and ${ }^{56} \mathrm{Fe}^{2+}$ on mass 28 and the two main isotopes of sulfur (mass 32 and 34) suffer from ${ }^{16} \mathrm{O}_{2}{ }^{+}$and ${ }^{16} \mathrm{O}^{18} \mathrm{O}^{+}+{ }^{1} \mathrm{H}_{2}{ }^{16} \mathrm{O}_{2}{ }^{+}$respectively, giving rise to detection limits of a hundred to a few hundred $\mu \mathrm{g} / \mathrm{g}$. Silicon and sulfur were therefore not measured. Silicon is not an extremely relevant element in the given context, since it is a typical slag element and it is not normally present in iron and steel from Western Europe. As mentioned before, the detection of ${ }^{31} \mathrm{P}^{+}$is somewhat hampered by ${ }^{14} \mathrm{~N}^{16} \mathrm{O}^{1} \mathrm{H}^{+}$, which results in higher detection limits. However, these interferences could be resolved by using a double-focusing sector field ICP-MS instrument.

Sample preparation is practically identical for both methods. In EPMA, the samples are usually additionally coated with carbon (or another non-interfering, conducting element) to prevent charge build-up on the sample surface. The sample throughput of both methods is more or less comparable. The analysis of 5 points on a sample by LA-ICP-MS with the parameter settings and the configuration used in this work, takes around $20 \mathrm{~min}$, including the time to mount the sample in the ablation cell and the time needed to flush the air out of the cell.

Strictly speaking, LA-ICP-MS is not as fully non-destructive a technique as EPMA, since a sub- $\mu \mathrm{g}$ - amount of material is removed from the sample. However, non-destructivity of the analysis itself is only of minor importance here, in view of the fact that the samples needed to be embedded, cut and polished prior to analysis in order to carry out the metallographic examination. EPMA has the benefit that the analysed spots can still be metallographically examined afterwards, or be measured with another technique at exactly the same locations on the sample.

Since areas with a diameter of only at most $50 \mu \mathrm{m}$ could be measured by the electron microprobe (compared to the $100 \mu \mathrm{m}$ laser ablation craters in this work), the EPMA measurements are somewhat more affected by inhomogeneous element distributions or microsegregations in the iron, if only a few points per sample are measured for the determination of the average concentration of an element in the iron phase.

The electron microprobe is a very convenient tool for elemental imaging (X-ray and backscatter electron imag- 
ing), a feature which can provide useful information on concentration gradients of specific elements in archaeological iron samples. Element mapping is also possible by LA-ICP-MS, and even with better sensitivity, but it can only be done indirectly, i.e. by shooting a matrix of craters, and with inferior spatial resolution compared to EPMA. The visualisation of element distributions then has to be done separately with graphics software, after reprocessing the measured signal intensities.

Nowadays, both methods have become standard equipment in many up-to-date earth or material science departments at universities and research institutes. The operational costs are comparable, whereas the purchase costs differ roughly by a factor of two in favour of LA-ICP-MS.

Analysis of archaeological iron samples: some preliminary results

Until now some 40 samples from Develier-Courtételle have been analysed. Some preliminary results are presented here; an extensive overview and discussion of results and their interpretation will be presented in the archaeometric literature.

In contrast to provenance determination of archaeological artifacts made from e.g., marble [30], clay [31], obsidian [31] or native metals, tracking smelted metals back to their raw materials source, in casu iron ore, by direct comparison of minor and trace element patterns is generally considered to be extremely difficult, if not impossible. Indeed, since not all elements have the same chemical behaviour during the smelting and refinement process from ore to iron, the element patterns change. Nevertheless, the iron composition can still reflect the original ore composition to some extent, e.g., in that extraordinary high (or low) concentrations of an element in the iron ore result in unusually high (or low) minor or trace levels

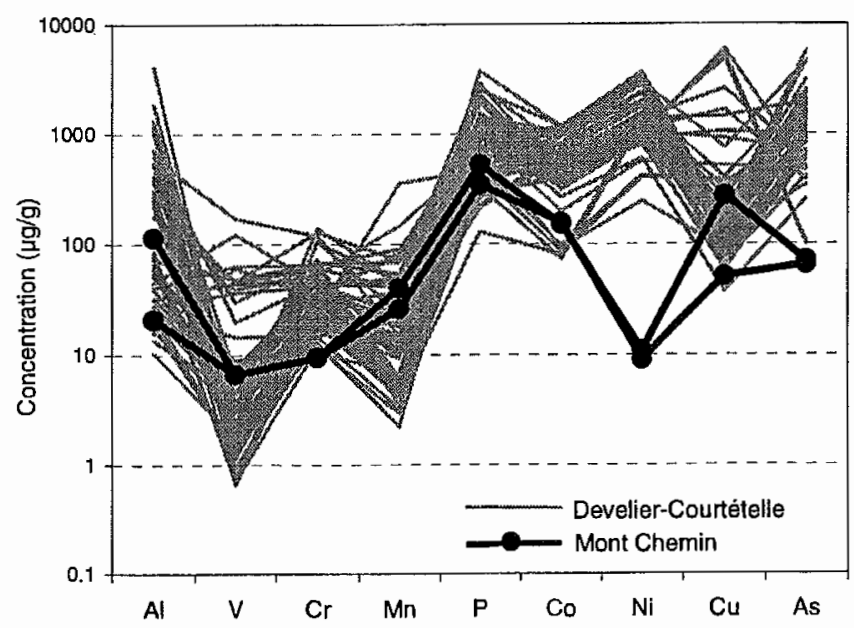

Fig. 9 Concentration profile for an iron bloom sample from Mont Chemin (Switzerland), compared to the concentration profiles in the Develier-Courtételle samples, showing low values for $\mathrm{Ni}$ in the Mont-Chemin sample

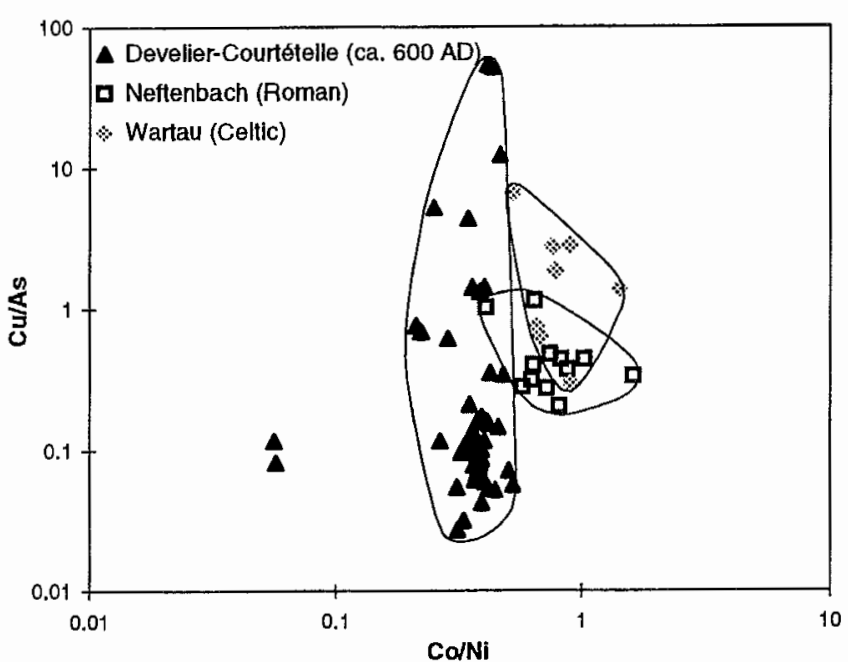

Fig. 10 Plot of the $\mathrm{Cu} / \mathrm{As}$-ratio versus $\mathrm{Co} / \mathrm{Ni}$-ratio in archaeological iron samples from Neftenbach (Roman), Wartau (Celtic) and Develier-Courtételle (early medieval), measured by LA-ICP-MS

of that element in the refined iron. This is illustrated in Fig. 9, which shows the element profile measured by LA-ICP-MS in an iron bloom fragment found at the site of Mont Chemin (Canton of Valais, Switzerland) in comparison with the element profiles in the Develier-Courtételle samples. The poor Ni concentration in the Mont Chemin bloom sample is in fact closely connected with the local, low-Ni iron ore [32]. Furthermore, iron objects (or intermediate iron products) from a same production site can sometimes be distinguished from samples with other provenances by their concentration patterns or concentration ratios of specific elements, even if a direct link to their respective ores cannot be made. To illustrate this, six samples from a Roman villa (ca. 50-300 AD) at Neftenbach (Canton Zurich, Switzerland) and 6 samples from a Celtic (ca. 500-0 BC) deposit at Wartau (Canton St Gallen, Switzerland) were analysed as well. Figure 10 shows that the samples from Develier-Courtételle can be distinguished almost unambiguously from the Wartau and Neftenbach samples in a plot of the $\mathrm{Cu} /$ As-ratio versus $\mathrm{Co} / \mathrm{Ni}$-ratio. The Wartau field can only be partially separated from the Neftenbach field. One tool fragment from Courtételle, which consisted of 2 layers, is characterised by a very low $\mathrm{Co} / \mathrm{Ni}$-ratio. This object might not be manufactured at Courtételle. Obviously, a larger set of data will be needed in order to better define the contours of the fields.

\section{Conclusions}

Archaeological iron samples could be analysed by LAICP-MS with the required spatial resolution in order to avoid analysing inclusions, while providing sufficient sensitivity and accuracy. The precision is mainly determined by sample (in)homogeneity. A limitation of the 
method is that iron or steel standards have to be used for calibration in which all the elements of interest are certified in the appropriate concentration range. This either limits the range of elements for analysis, or requires the measurement of additional standards, which reduces sample-throughput.

Preliminary measurements on archaeological iron samples gave promising indications that iron findings from a different origin could sometimes be distinguished by their minor and trace element composition. More data from other iron findings will be necessary though, to relate an unknown sample to a specific provenance.

In the future it will be attempted to further establish the relation between the composition of the iron and its ore by comparing LA-ICP-MS analyses of archaeological iron samples with data from literature on the composition of iron ores in Switzerland, and by analysis of experimentally produced iron from a known ore source, using the traditional direct reduction process.

Acknowledgements The authors wish to acknowledge the Department of Archaeology of the Cantons Jura and Zurich, the Department of Prehistory of the University of Zurich and the Centre d' Analyse Minérale of the University of Lausanne for providing the samples from Develier-Courtételle, Neftenbach, Wartau and Mont Chemin respectively.

\section{References}

1. Senn-Luder M, Escheniohr L (1999) In: Crew P, Crew S (eds) Proceedings of the International Conference Early Iron Working in Europe, Archaeology and Experiment (19-25 Sept. 1997), Plas Tan y Bwlch, Wales, UK (in press)

2. Serneels V, Eschenlohr L, Senn-Luder M (1997) In: Technique des Fouilles; Minerai, Scories, Fer/Grabungstechnik; Erze, Schlacke, Eisen, Vereinigung des Archäologisch-technischen Grabungspersonals der Schweiz (VATG), Basel, Switzerland, pp $9-12,17-37$

3. Cahill TA (1980) Ann Rev Nucl Part Sci 30:211-252

4. Demortier G (1988) Nucl Instrum Meth in Phys Res B 30: 434-443

5. Narayan C, O'Connor M, Kegel GHR, Johnson R, Salmons C, White C (1996) Nucl Instrum Meth in Phys Res B 118:396399

6. Swann CP (1997) Nucl Instrum Meth in Phys Res B 130:289296
7. Guerra MF (1998) X-Ray Spectrom 27:73-80

8. Demortier G (1999) Nucl Instrum Meth in Phys Res B 150: $520-531$

9. Hedges REM, Salter CJ (1979) Archaeometry 21(2): 161-175

10. Fell V, Salter CJ (1998) Journal of the Historical Metallurgy Society $32: 1-6$

11. Crew P, Salter CJ (1993) In: Espelund A (ed) Bloomery Ironmaking During 2000 Years, Volume III, proceedings of the Budalen Seminar, 26-30 August 1991, Budalen, Trondheim, Norway, p 11-30

12. Arrowsmith $P$ (1987) Anal Chem $59: 1437-1444$

13. Denoyer ER, Fredeen KJ (1991) Anal Chem $63: 445$ A-457 A

14. Moenke-Blankenburg L (1993) Spectrochim Acta 15:1-37

15. Cromwell EF, Arrowsmith P (1995) Anal Chem 67:131-138

16. Perkins WT, Pearce NJG, Westgate JA (1997) Geostandards Newsletter - The Journal of Geostandards and Geoanalysis 21: $175-190$

17. Raith A, Hutton RC (1994) Fresenius J Anal Chem 350:242246

18. Raith A, Godfrey J, Hutton RC (1996) Fresenius J Anal Chem 354:163-168

19. Denoyer ER (1992) J Anal At Spectrom $7: 1187-1193$

20. van Heuzen AA (1991) Spectrochim Acta 46B : 1803-1817

21. van Heuzen AA, Morsink JBW (1991) Spectrochin Acta 46B: $1819-1828$

22. Günther D, Cousin H, Magyar B, Leopold I (1997) J Anal At Spectrom 12:165-170

23. Günther D, Audétat A, Frischknecht R, Heinrich CA (1998) J Anal At Spectrom 13:263-270

24. Masters BJ, Sharp BL (1997) Analytical Communications 34 : 237-239

25. Leach JJ, Allen LA, Aeschliman DB, Houk RS (1999) Anal Chem $71: 440-445$

26. Ishibashi Y (1997), ISU International 37:885-891

27. Shell CA, Taylor JJ, Warner RB, Watling RJ (1998) In: Mordant $C$, Pernot $M$, Rychner V (eds) L'Atelier du bronzier en Europe du XXe au VIIle siècle avant notre ère, Actes du colloque international Bronze ' 96 , CTHS, Paris, p 247-258

28. Wanner B, Moor Ch, Richner P, Brönnimann R, Magyar B (1999) Spectrochim Acta B 54:289-298

29. Völlkopf U, Barnes K (1995) At Spectrosc 16:19-21

30. Moens L, De Paepe P, Waelkens M (1992) In: Waelkens M, Herz N, Moens L (eds) Ancient Stones: Quarrying, Trade and Provenance, Acta Archaeologica Lovaniensia 4, Leuven University Press, Leuven, Belgium, p 247-252

31. Pollard AM, Heron C (1996) Archaeological Chemistry, Royal Society of Chemistry, Cambridge, UK

32. Beck B (1997) Réduction de la magnétite dans un bas fourneau au Mont Chemin (Valais - Suisse). Licenciate thesis, University of Lausanne 